\title{
¿La fotografía más antigua del Quijote: Figueras, 1889?*
}

\author{
JoAn Manuel Soldevilla Albertí**
}

\section{Resumen}

Las fotografías de don Quijote y Sancho Panza permiten analizar la iconografía asociada a los personajes de ficción. En el Àlbum Rubaudonadeu, un extenso reportaje fotográfico realizado por Josep Maria Cañellas sobre la vida cotidiana en el Ampurdán a finales del siglo XIX, se encuentra una de las primeras fotografías conservadas de los héroes cervantinos, una instantánea tomada en el marco de las fiestas de carnaval de Figueras en 1889.

Palabras clave: don Quijote; fotografía; carnaval; Josep Rubaudonadeu; Josep Maria Cañellas; Figueras.

Title: Is this the oldest photograph of Don Quijote: Figueras, 1889?

\begin{abstract}
The photographs of Don Quijote and Sancho Panza enable an analysis of the iconography associated with these fictional characters. One of the first preserved photos of the two Cervantine heroes can be found in the Album Rubaudonadeu, an extensive photographic report about everyday life in the area of Empordà in the late $19^{\text {th }}$ century, which was compiled by Josep Maria Cañellas. The photograph was taken during the Carnival festival in Figueras in 1889.
\end{abstract}

Keywords: Don Quijote; Photography; Carnival; Josep Rubaudonadeu; Josep Maria Cañellas; Figueras.

* La presente nota ha sido posible gracias a la colaboración de la Biblioteca Fages de Climent, sita en Figueras, y especialmente de su directora, Nati Vilanova. Igualmente ha contado con la orientación inestimable del doctor José Manuel Lucía Megías.

** Instituto Ramon Muntaner de Figueras.jsoldevi@xtec.cat / ORCID iD: https://orcid.org/00000003-4745-8900. 


\section{Cómo citar este artículo / Citation}

Soldevilla Albertí, Joan Manuel (2018). «¿La fotografía más antigua del Quijote: Figueras, 1889?», Anales Cervantinos. 50, pp. 327-331, https://doi.org/10.3989/anacervantinos.2018.014.

El estudio de las fotografías sobre el universo cervantino y quijotesco constituye un sugerente territorio que aún ofrece a los investigadores notables sorpresas. A diferencia de las recreaciones gráficas del Quijote, abundantes desde fecha temprana y que han sido ampliamente estudiadas y documentadas $^{1}$, la fotografía nos ofrece un campo abierto a múltiples exploraciones y descubrimientos, sobre todo desde que se han empezado a digitalizar colecciones y fondos que hasta hace poco eran prácticamente inaccesibles.

La historia de la fotografía constituye uno de los episodios decisivos en el desarrollo tecnológico del siglo XIX y su influencia en el pensamiento, la pintura, la literatura y la sociedad en general, supone uno de los elementos decisivos para entender las transformaciones culturales de ese período. Sin entrar en un detallado recorrido histórico, y solo marcando unos hitos decisivos, es bueno apuntar cómo la fotografía que nace en 1839 con los daguerrotipos - que exigían una larga exposición para capturar imágenes-, evoluciona velozmente hasta que en 1851 se crea la posibilidad técnica de capturar instantáneas y da un salto definitivo cuando en 1888 Kodak crea los carretes que progresivamente sustituirían a las placas.

Con este nuevo prodigio tecnológico, las primeras fotografías cervantinas que se conservan perseguían retratar los diversos escenarios del Quijote o aquellos lugares en los que vivió Cervantes, según se puede consultar en el fondo fotográfico de la Biblioteca Nacional ${ }^{2}$. Son, por lo tanto, instantáneas con valor documental que buscan mostrar y conservar la memoria de aquellos espacios reales que se convirtieron en marco de la vida del autor o de sus ficciones: los campos de Criptana, la casa de Cervantes en Barcelona o los molinos de viento manchegos constituyen ámbitos dignos de ser fijados y posteriormente divulgados. Igualmente interesantes son las fotografías que reproducen grabados y pinturas tanto de Cervantes como de diversos pasajes de la novela.

En esos primeros años, otra tendencia interesante en el campo de la fotografía es aquella que podríamos calificar como artística; en ella, el fotógrafo, o bien en estudios especialmente acondicionados para ello o, a modo de los pintores impresionistas, a plein air, retrata individuos u objetos - al estilo

1. En este sentido, solo hace falta recordar los estudios de Canavaggio (2006) y Lucía Megías (2006), la exposición de la Biblioteca Nacional Coleccionismo Cervantino en la BNE y el catálogo homónimo o el monumental proyecto Banco de imágenes del Quijote: 1605-1915), dirigido por el doctor José Manuel Lucía Megías, accesible en: <http://qbi2005.windows.cervantesvirtual.com>. Fecha de acceso: 24/09/2018.

2. Accesible en: <http://cervantes.bne.es/es/colecciones/fotografia $>$. Fecha de acceso: 24/09/2018. 
pictórico, son frecuentes los desnudos y bodegones- o bien paisajes, creando composiciones que persiguen un evidente ideal estético. Dentro del campo específicamente cervantino, en Francia fueron diversas las cartes de visite, es decir, retratos fotográficos, que reproducían la supuesta imagen de Cervantes e incluso, en ocasiones, de sus personajes de ficción. Ya en España, y en un proyecto de mayor envergadura, es destacable el trabajo de Luis de Ocharán Mazas, estudiado por Rubio y Zamora, quien en 1905 y 1906 recreó diversos pasajes de la novela con actores, vestuario y atrezo en una colección de estampas ejemplares.

Una reciente investigación que ahora presentamos pone al descubierto una fotografía quijotesca de innegable valor documental. Es una imagen integrada en el llamado Album Rubaudonadeu y en ella se nos muestra a don Quijote y Sancho Panza, montados encima de un caballo y un asno, paseando por las calles de Figueras; la instantánea está tomada durante las fiestas de carnaval de 1889 y constituye, al menos por ahora y hasta nuevos descubrimientos, la fotografía más antigua de los héroes cervantinos realizada en España.

El Album Rubaudonadeu ${ }^{3}$ es un impresionante documento gráfico que encargó Josep Rubau Donadeu (1841-1926), un prohombre ampurdanés que desarrolló una intensa vida como activista cultural y político, llegando a ser diputado a las Cortes Españolas en dos ocasiones. En 1888 encomendó a Josep Maria Cañellas, por aquellos años prestigioso fotógrafo reusense afincado en París, que elaborase un exhaustivo reportaje fotográfico del Ampurdán, tanto de su capital, Figueras, como de los diversos pueblos de la comarca. Después de tres meses de trabajo exhaustivo a caballo de los años 1888 y 1889, Cañellas, cámara en ristre, consiguió recoger una exhaustiva e innovadora colección de quinientas cincuenta y cinco fotografías de alto valor histórico y etnográfico, un documento único que no solo retrata la vida cotidiana de los habitantes de la zona de una manera ejemplar sino que se convierte en un trabajo que sienta las bases del fotoperiodismo; su obra, reivindicada en la exposición Josep Maria Cañellas. Reus 1865-París 1902. Photographie des artistas (Figueras, 2005) y en su correspondiente catálogo, constituye una referencia imprescindible.

La fotografía que nos ocupa en este artículo está recogida con el epígrafe Figueras. N. ${ }^{\circ}$ 62. Cabalgata del Casino Erato. Carnaval 1889. Don Quijote y Sancho Panza y en ella podemos ver a los héroes cervantinos, vestidos según la imagen consolidada por la iconografía tradicional, paseando por la parte alta de la Rambla de Figueras, en lo que parece inequívocamente un desfile carnavalesco si atendemos al numerosísimo público asistente al pasacalle.

3. En la actualidad se conserva en la Biblioteca Fages de Climent de Figueras y se puede consultar en línea en <http://www.bibgirona.cat/regira/repositori/figueresfagesdecliment/colleccio/albumrubaudonadeu $>$. Fecha de acceso: 24/09/2018. 


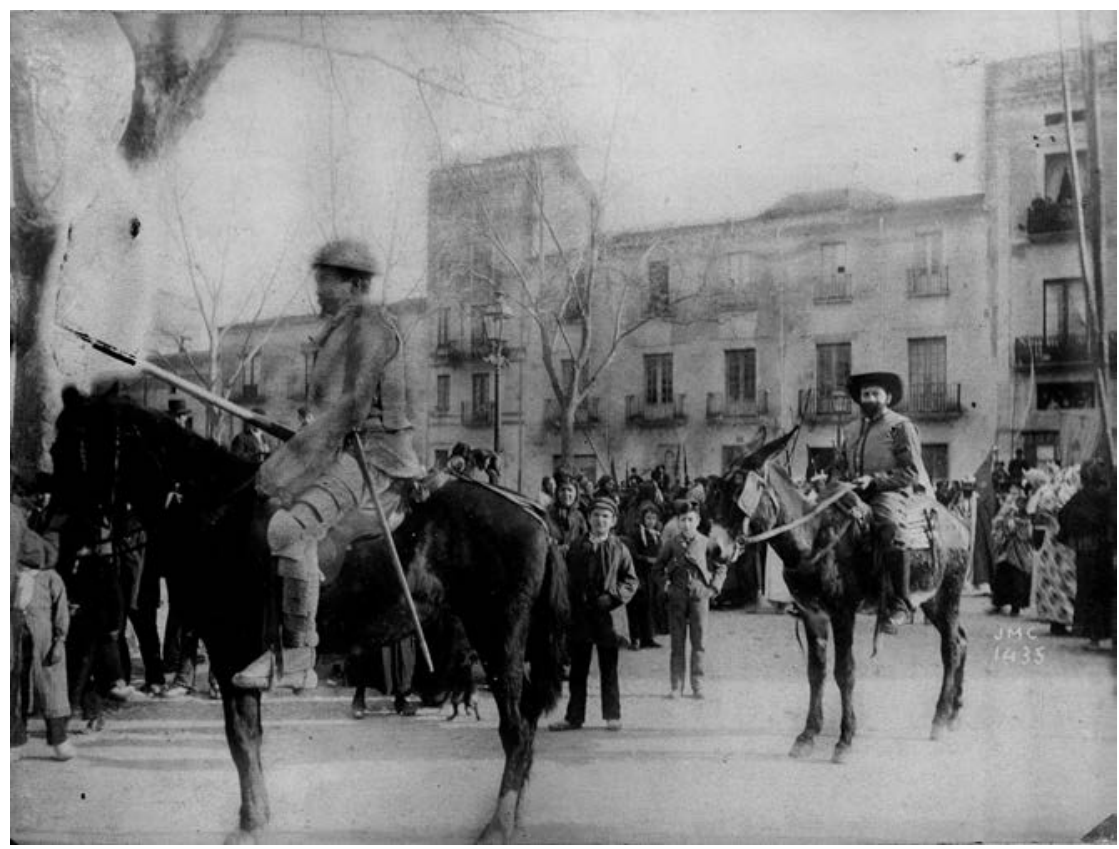

Cabalgata del Casino Erato. Carnaval 1889. Don Quijote y Sancho Panza.

Que la indicación subraye que la cabalgata está organizada por la Societat Coral Erato no es un dato baladí; fundada en 1862, esta asociación cultural destacó por su cervantismo militante y así en 1905 fue una de las entidades que impulso la propuesta de cambiar el nombre de la calle San Pablo — una de las arterias importantes de la ciudad - por el de calle Cervantes. Este nombre se mantuvo hasta 1939 cuando, tras la guerra, recuperó su nombre primigenio, que se mantiene — ahora en catalán, Sant Pau-, hasta hoy en día. En la actualidad, y valga como anécdota, a la puerta de la Societat Coral, una imponente estatua de don Quijote recibe a los visitantes.

La instantánea que nos ocupa tiene, además de la significación histórica de ser la primera fotografía conservada de alguien vestido de don Quijote, un incuestionable valor añadido dentro del ámbito cervantino, pues recoge una estampa de las fiestas de carnaval. Se ha escrito mucho sobre la relación de lo carnavalesco con el universo de la obra, donde los personajes, desde el mismo protagonista hasta el cura y el barbero, pasando por Dorotea, la dueña Dolorida y tantos otros, tienen una natural inclinación a cambiarse de vestimenta y adoptar nuevas personalidades; pero más allá de esta evidencia, los carnavales, celebraciones, charadas y mascaradas donde los individuos se disfrazaban a inicios del siglo XVII han servido para demostrar la extraordinaria popularidad de los personajes cervantinos; de Zaragoza a Córdoba, pasando por Sevilla, Utrera o Baeza, la gente se disfrazaba de don Quijote y Sancho cuando tenía ocasión. Y desde fecha temprana y lugares remotos: en 
1607, en Pausa, en el virreinato del Perú, para celebrar la llegada del nuevo virrey se organizó una gran mascarada donde hizo acto de presencia un don Quijote acompañado de una buena corte de personajes cervantinos:

A esta ora asomó por la plaça el Cavallero de la Triste Figura don Quijote de la Mancha, tan al natural y propio de como le pintan en su libro, que dio grandísimo gusto berle. Benía cavallero en un cavallo flaco muy parecido a su Rozinante, con unas calcitas del año de uno, y una cota muy mohoza, morrión con mucha plumería de gallos, cuello del dozabo, y la máscara muy al propósito de lo que representaba. Aconpañábanle el cura y el barbero con los trajes propios de escudero, e infanta Micomicona que su corónica quenta. Y su leal escudero Sancho Panza, graciosamente bestido, cavallero en su asno albardado y con sus alforjas bien proveídas y el yelmo de Manbrino (... $)^{4}$.

La fotografía de Cañellas integrada en el Àlbum Rubaudonadeu, inicialmente una más dentro del magno reportaje que quería retratar los usos y costumbres de la vida ampurdanesa, documenta de forma rotunda la tradición de disfrazarse de don Quijote y Sancho en 1889, señal evidente de la permanente popularidad del personaje en todos los ámbitos sociales.

En Figueras volvió a cabalgar don Quijote de la Mancha, tan al natural y propio de como le pintan en su libro (...) Y su leal escudero Sancho Panza, graciosamente bestido, cavallero en su asno albardado y con sus alforjas. Habían pasado doscientos ochenta y dos años desde las fiestas del Perú pero ahora, por primera vez, una cámara fotográfica capturaba este momento.

\section{BIBLIOGRAFÍA CITADA}

Canavaggio, Jean (2006). Don Quijote, del libro al mito. Madrid: Espasa-Calpe. [Original en francés, Don Quichotte. Du libre au mythe. París, 2005].

Capella, Anna y Jaume Santaló (coords.) (2005). Josep Maria Cañellas. Reus 1865-París 1902. Photographie des artistes. Figueras: Museu de l'Empordà.Triangle postals.

Coleccionismo cervantino en la BNE: del Doctor Thebussem al fondo Sedó. Madrid: Biblioteca Nacional. Catálogo de la exposición homónima comisariada por José Manuel Lucía Megías (2015).

Lucía Megías, José Manuel (2006). Leer el "Quijote” en imágenes. Madrid: Calambur.

Lucía Megías, José Manuel y Aurelio Vargas (2005). "Don Quijote en América: Pausa, 1607" (facsímil y edición). "Relación de las fiestas que se celebraron en la corte de Pausa", Literatura: teoría, historia y crítica. 7, pp. 203-244.

Rubio, Abraham y Alonso Zamora (2007). Ocharán, Zuloaga y el Quijote. Segovia: Caja Segovia.

Recibido: 26 de febrero de 2018

Aceptado: 16 de marzo de 2018

4. Lucía y Vargas (2005): 238. 